\title{
Creation of an ex-vivo bovine kidney flow model for testing embolic agents: work in progress
}

\author{
Luis Garza ${ }^{1 \dagger}$, Ryan Bitar ${ }^{1 \dagger}$, Barrett O’Donnell ${ }^{2}$, Matthew Parker ${ }^{2}$, Carlos Ortiz ${ }^{2}$, Charles Hyman², John Walker ${ }^{2}$,
} Ho-Young Song ${ }^{2,3}$ and Jorge Lopera ${ }^{1,2^{*}}$ (D

\begin{abstract}
Objectives: To develop an ex- vivo perfusion flow model using a bovine kidney for future testing of embolic agents in an inexpensive and easy way.

Methods: Six bovine adult kidneys were used for this study. Kidneys were cannulated and perfused via a roller pump. Three embolic agents, coils, Gelfoam, and a glue mixture of Histoacryl + Lipiodol, were deployed by targeting three secondary segmental arteries per kidney via a 5Fr catheter under fluoroscopic guidance.

Cannulation time, success rate of segmental artery selection and embolic agent deployment, total operational time, and fluoroscopy dose were recorded.

Results: Average kidney weight was $0.752+/-0.094 \mathrm{~kg}$. All six bovine kidneys were successfully cannulated in 21.6 min $+/-3.0 \mathrm{~min}$. Deployment of coils and glue was achieved in every case (12/12); however, Gelfoam injection was not successful in one instance $(5 / 6,83 \%)$. Coil deployment demonstrated no embolic effect while Gelfoam and glue injections demonstrated decreased distal contrast filling post-embolization. Mean dose area product was $12.9 \pm 1.8$ Gy.cm2, fluoroscopy time was $10 \pm 4 \mathrm{~min}$ and operational time was $27 \pm 8 \mathrm{~min}$.

Conclusions: We describe the creation of an ex vivo bovine kidney flow model for the preclinical evaluation of different embolic materials. The flow model can be modified to provide extensive bench testing and it is a promising tool for hands -on training in basic and advanced embolization techniques .
\end{abstract}

Keywords: Flow model, Perfusion, Bovine kidney, Embolization, Fluoroscopy

\section{Introduction}

Therapeutic vascular embolization procedures represent established treatment options for a variety of conditions such as hemorrhage, tumor, and vascular malformations (Moreira and An 2003). Preclinical testing of embolic materials has been extensively described in live animals (Oh et al. 2015; Barbosa L de et al. 2009; Sommer et al.

\footnotetext{
* Correspondence: Lopera@uthscsa.edu

${ }^{\dagger}$ Luis Garza and Ryan Bitar contributed equally to this work.

'Long School of Medicine, University of Texas Health Science Center, 7703

Floyd Curl Drive San Antonio, San Antonio, TX 78229, USA

2Department of Radiology, University of Texas Health Science Center, San

Antonio, TX, USA

Full list of author information is available at the end of the article
}

2011; Siskin et al. 2003). It is essential to study and test novel embolic materials in animal tissue prior to human clinical trials; however formalized in-vivo trials may be taxing and resource consuming. Bench testing to characterize the behavior of novel embolic materials in an organ flow model may aid in selecting promising materials to then proceed into live animal studies. It may prove beneficial to establish a simple ex-vivo perfusion model for the pre-clinical evaluation of embolic agents.

To our knowledge, there is no description of an exvivo perfusion model of a bovine kidney to deploy embolic materials. The bovine kidney's total volume and vascularity size facilitate the testing of embolic agents, without requiring specialized angiography catheters

\section{Springer Open}

(c) The Author(s). 2021 Open Access This article is licensed under a Creative Commons Attribution 4.0 International License, which permits use, sharing, adaptation, distribution and reproduction in any medium or format, as long as you give appropriate credit to the original author(s) and the source, provide a link to the Creative Commons licence, and indicate if changes were made. The images or other third party material in this article are included in the article's Creative Commons licence, unless indicated otherwise in a credit line to the material. If material is not included in the article's Creative Commons licence and your intended use is not permitted by statutory regulation or exceeds the permitted use, you will need to obtain permission directly from the copyright holder. To view a copy of this licence, visit http://creativecommons.org/licenses/by/4.0/. 
(Szymanski et al. 2018). Additionally, the arterial vasculature of the bovine kidney is similar to the human kidney including total number of primary segmental arteries (Szymanski et al. 2018). Unlike humans, the bovine renal artery splits before the hilum decreasing the technical difficulty of revealing the vessels with dissection of the renal hilar structures (Carvalho et al. 2009). Thus, we hypothesized that it would be possible to successfully test the deployment of commercially available embolic materials in a bovine kidney under fluoroscopy using standard angiography tools. We aimed to develop a flow model using a bovine kidney connected to a perfusion pump for the purpose of future testing of embolic agents in an inexpensive and easily reproducible model. The model could be also used as a hands-on training tool to teach the residents fellows the basics of embolization techniques.

\section{Methods}

\section{Preparing the pump apparatus}

A decommissioned perfusion roller pump (COBE Laboratories, Arvada, CO) was used. An acrylic basin to contain the kidney was prepared by drilling two holes into the side of the basin, to accommodate insertion of the arterial and venous tubing from the pump into the basin. Using a Y connector, the venous inflow tubing was divided into 2 segments: one for cannulation to the renal vein and one free end of inflow tubing for aspiration of water from the basin. A small puncture was made along the large outflow tubing to insert a $7 \mathrm{Fr}$ vascular sheath (Terumo, Somerset, NJ) to provide intravascular access.

\section{Kidney preparation/cannulation}

Adult bovine kidneys were harvested within $4 \mathrm{~h}$ from a local slaughterhouse (Wiatrek Processing Plant, Poth, TX) and transported to our laboratory on ice and stored at $-20^{\circ} \mathrm{C}$ until further use. A total of six kidneys were collected, five left and one right. Left kidneys were preferred, as it was easier to cannulate them given the longer renal veins. Kidneys were not frozen more than 1 week, and all were thawed $24 \mathrm{~h}$ prior to experiments. A 16Fr Foley catheter (McKesson, Grapevine, TX) was used to cannulate the renal vein and secured by inflating the Foley balloon followed by purse string suture and a zip tie around the outer wall of the vein. The renal artery was cannulated with a piece of $15 \mathrm{Fr}$ stiff tube and secured with a purse string suture and two zip ties.

\section{Initiating kidney perfusion}

The cannulated kidney was submerged in tap water inside the basin. The free end of the now cannulated Foley catheter was connected to the venous tubing with a Yconnector submerged in water. The basin was filled with $25^{\circ} \mathrm{C}$ tap water to submerge the kidney and the free aspirating end of the $\mathrm{Y}$ connector. The system was purged of air by activating the pump at a flow rate of $0.40 \mathrm{~L} / \mathrm{min}$ prior to attaching the arterial inflow connection to the renal artery. Once air bubbles were purged out of the tubing, the pump was deactivated. The proximal end of the $15 \mathrm{Fr}$ arterial cannula was connected to the arterial outflow tubing. Then, the pump was activated to a flow rate of approximately $0.49 \mathrm{~L} / \mathrm{min}$ based on our pilot test. The assembled flow model is depicted in Fig. 1.

\section{Delivery of embolic materials}

Angiography was conducted via a Siemens Arcadis $\mathrm{C}$ arm provided by our institution's Department of Laboratory Animal Resources. This study involved the evaluation of three embolic materials: Tornado embolization coils (Cook Medical, Bloomington, IN), Gelfoam (Pfizer, New York, NY), and a glue mixture of Histoacryl (B Braun, Bethlehem, Pennsylvania) + Lipiodol (Guerbert, Princeton, NJ). Angiography and embolization for each kidney were attempted individually by a first-year diagnostic radiology resident and two medical students under the supervision of an interventional radiologist with 23 years of experience in vascular interventions. Each of the embolic materials were delivered to one of three segmental arterial branches in a single kidney (Fig. 2). A 5Fr cobra catheter (Boston Scientific, Marlborough, MA) with a Glidewire (Terumo, Somerset, NJ) was used for selection of segmental arteries and delivery of embolic materials. Once the catheter was placed in the renal artery, digital subtraction angiography (DSA) road mapping with Omnipaque contrast media (GE Healthcare, Wood Dale, IL) was conducted to outline arterial anatomy, assess for any intraparenchymal or extraparenchymal extravasation, and assist in selection of segmental branches for deploying the various embolic agents. For coil embolization, 3-4 mm 0,035-in. pushable coils were deployed using a Benston wire (Cook Medical, Bloomington, IN). Gelfoam particles were prepared by forcefully mixing a $2 \mathrm{~cm} \mathrm{X} 2 \mathrm{~cm}$ piece of Gelfoam in a syringe filled with $5 \mathrm{~mL}$ of contrast media using a 3 -way stopcock until a slurry was created. The Gelfoam slurry was slowly deployed with pulsatile boluses under fluoroscopy until stasis was observed. The volume of Gelfoam required to achieve stasis was recorded. For the deployment of glue, a mixture of $2 \mathrm{~mL}$ of lipiodol and $1 \mathrm{~mL}$ of Histoacryl was injected at a slow continuous rate until a cast of glue and subsequent stasis was visualized in the targeted segmental arteries. Glue infusion was preceded and succeeded with a 3 $\mathrm{mL}$ flush of the catheter with D5W. 


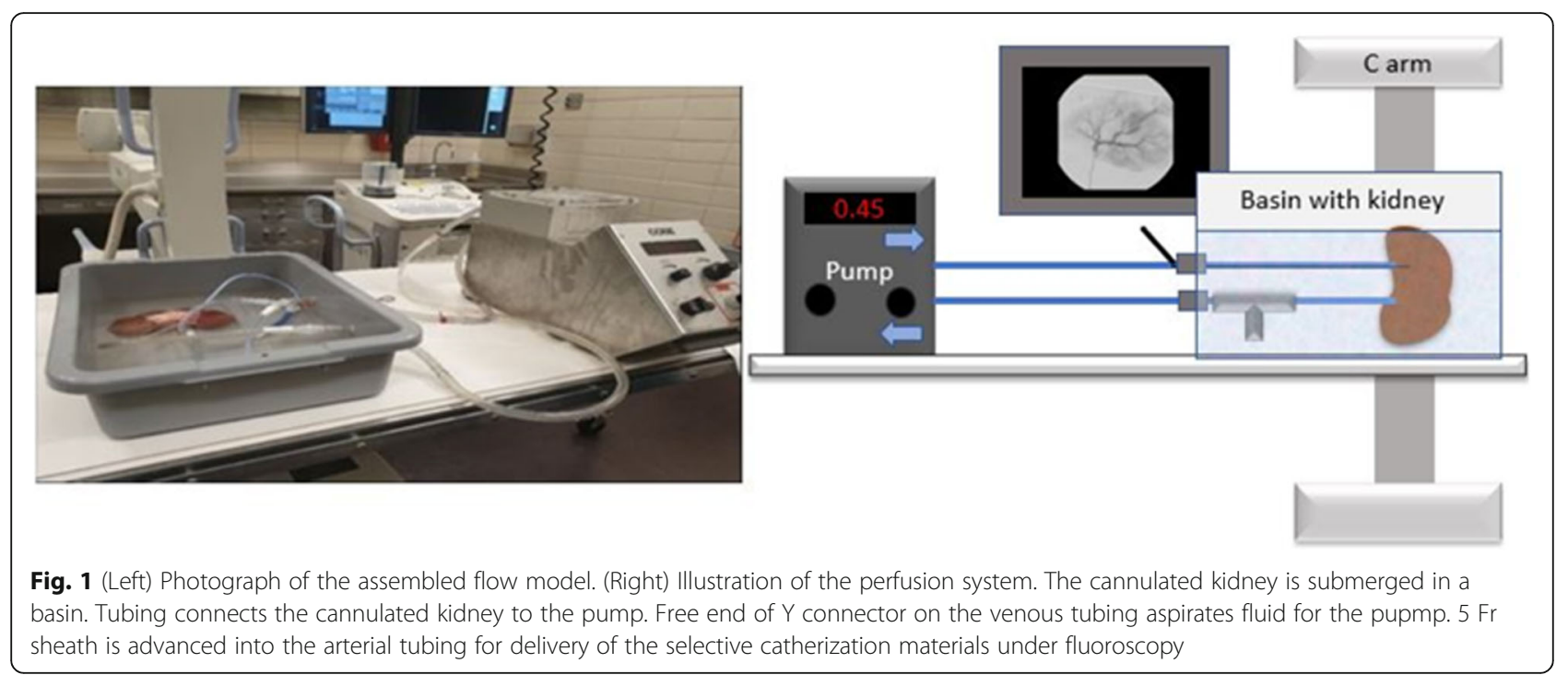

\section{Data acquisition/analysis}

Kidney weight upon delivery to the lab was recorded. Approximate freeze time was recorded to assess an effect on kidney tissue quality, feasibility of angiography, and arterial segmental selection. Cannulation time was collected to assess the reproducibility and difficulty of constructing the model. A pre-embolic DSA was performed to assess the variability in vascular anatomical architecture. The success rate of segmental artery selection was reported to determine whether it was feasible to execute at minimum three embolic experiments within individual segments of each single kidney. The success rate of embolic agent deployment was recorded to assess the model's ability to serve as an embolic deployment mimic. Post-embolic nonselective DSA images were performed and interpreted to assess the embolic effect of the agents. Total operational time and fluoroscopy dose were recorded to assess the feasibility, practicality, and safety of the experiment. Additionally, the above data points were collected for a single right kidney for direct comparison to left kidney procedural outcomes.

\section{Results}

The average weight of the six collected kidneys was $0.752 \mathrm{~kg} \pm 0.094 \mathrm{~kg}$. Five kidneys were cannulated with no complications and an average cannulation time of $21.6 \mathrm{~min}+/-3.0 \mathrm{~min}$. Kidney six, with a cannulation time of $46 \mathrm{~min}$, was excluded as an outlier in this analysis due to multiple spontaneous decannulations of the arterial side. Kidneys were perfused with an average flow rate of $0.49 \pm 0.07 \mathrm{~L} / \mathrm{min}$. Non-selective DSA demonstrated overall homogeneity in the vascular anatomy of bovine kidneys, with the renal artery dividing into a

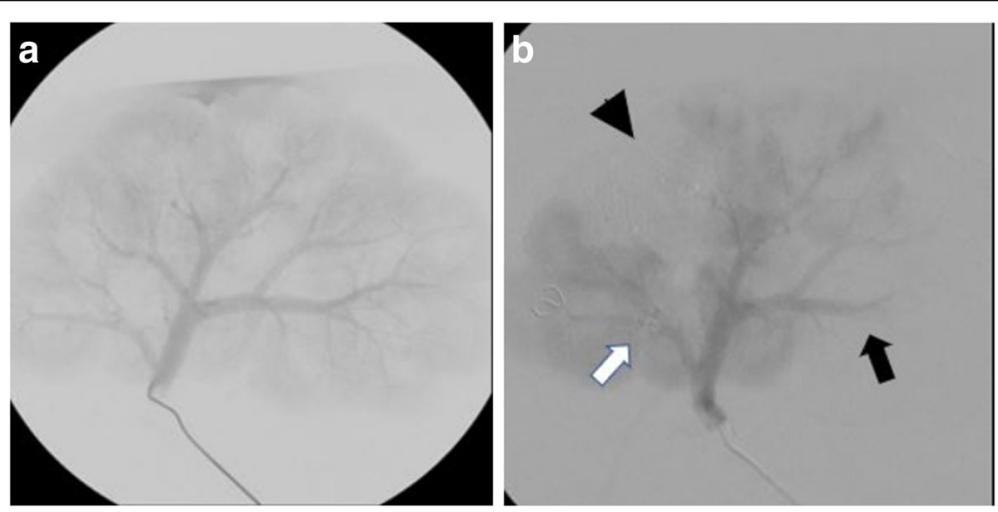

Fig. 2 a Nonselective pre-embolization DSA run displaying renal arterial vasculature. b Nonselective post-embolization DSA run. Deployment of coil in cranial posterior segmental artery (white arrow) does not demonstrate appreciable embolic effect. Deployment of Gelfoam (black arrow) demonstrates decreased distal filling of the caudal posterior segmental artery. Glue (arrowhead) demonstrates complete embolization of the caudal secondary segmental artery 
cranial and a caudal primary segmental arteries to supply the cranial and caudal poles, respectively. It was observed that typically the mid-zone of the kidney was supplied via a secondary segmental artery which came off the caudal primary segmental artery. In five kidneys, three distinct segmental arteries were identified and successfully individually selected via a 5Fr cobra catheter with Glidewire assist. All embolic materials were deployed as per Table 1. While the volume of glue mixture was fixed at approximately $3 \mathrm{~mL}$, the average amount of Gelfoam required to achieve stasis was variable with an average deployment volume of $12 \mathrm{~mL}(+/-3.5 \mathrm{~mL})$. Post-op analysis revealed average dose area product to be 12.9 Gy.cm $2 \pm 1.8 \mathrm{~Gy} \cdot \mathrm{cm} 2$ and total fluoroscopy time to be $10 \mathrm{~min} \pm 4 \mathrm{~min},(n=4)$. Overall operational time (time from first to last image) was $27 \pm 8 \mathrm{~min}$ (Table 2).

As per post-embolic DSA runs, no stasis was appreciated with any of the metallic coils and a significant amount of Gelfoam was required to achieve stasis; complete stasis was observed in segments treated with glue (Fig. 2). Of note, upon pre-embolic DSA runs, contrast extravasation was present in the secondary segmental artery of kidney three and diffusely in kidneys five and six. Extravasation was not observed in branches after embolization (Fig. 3).

\section{Discussion}

We developed an ex- vivo flow model using a bovine kidney for the purpose of future testing embolic agents in an inexpensive and easily reproducible model. The above results validate the model via DSA which clearly visualized the arterial anatomy and demonstrated a pulsatile flow with parenchymal blush and venous return on all the kidneys. Contrast extravasation was noted in some kidneys due varying degrees of parenchymal damage prior and upon perfusion that were related to tissue degradation of the frozen tissues, despite this limitation, we noticed that foci of contrast extravasation decreased after deployment of embolic materials, which implies that embolic agents were retained in the vascular bed of the selected artery, and that novel embolic materials could be preliminarily tested using a similar flow model to characterize embolic agent behavior and vascular distribution effects. In theory, the areas of contrast extravasation could also serve as teaching model to simulate bleeding control with embolization.

The preparation and operation of this flow model was consistently successful in the hands of a radiology resident and two medical students under the supervision of an experienced interventional radiologist. Thus, it can serve as an educational tool for radiation safety teaching, DSA, road mapping and selective angiography training, and practice techniques deploying embolic materials in a low-risk context. The bovine renal anatomy demonstrated easy identification and isolation of arterial vasculature supplying each kidney segment leading to precise application and testing of Gelfoam, glue, and embolization coils. Compared with animal models, advantages of this ex- vivo flow kidney model include lower associated costs, minimal structural requirements, and ease of preparation without the ethical concerns related to live animal use.

Notably, all six kidneys showed similar embolization efficacy results upon post-embolic DSA runs, particularly a diminishing degree of stasis as time passed after Gelfoam embolization. Under normal physiologic settings, Gelfoam promotes hemostasis by hastening the development of and providing structural support to thrombus formation (Kohda et al. 1986). Gelfoam has been successfully used in various clinical scenarios including hemorrhage secondary to trauma (Ben-Menachem et al. 1991), bone cancer (Feldman et al. 1975), renal cell carcinoma (Bracken et al. 1975), and uterine fibroid artery embolization (Siskin et al. 2000). The absence of an intact coagulation cascade in the perfusion model likely played a significant role in the deteriorating embolic effects of the Gelfoam. The lack a coagulation cascade also explains the failure of the coils in achieving stasis. This limitation must be taken into consideration when testing embolic materials that require specific physiological environments which are not present with ex -vivo models. The use of blood in this model may provide a better environment to test the effects of different embolization agents.

Table 1 Characterization of Embolic Agent Targets by Renal Poles

\begin{tabular}{lllll}
\hline & Cranial & Mid-Zone & Caudal & Cannulation Success (Cranial, Mid, Caudal) \\
\hline 1st Kidney & Coil & Glue & Gelfoam &,,+++ \\
2nd Kidney & Coil & Glue & Gelfoam &,,+++ \\
3rd Kidney & Gelfoam & Coil & Glue &,,+++ \\
4th Kidney & Gelfoam & Coil & Glue &,,-++ \\
5th Kidney & Gelfoam & Coil & Glue &,,+++ \\
6th Kidney & Gelfoam & Coil & Glue &,,+++ \\
\hline
\end{tabular}

$+=$ Successful Cannulation

- = Unsuccessful Cannulation 
Table 2 Perfusion model data and specifications

\begin{tabular}{|c|c|c|c|c|c|c|}
\hline & $\begin{array}{l}\text { Perfusion rate (L/ } \\
\text { min) }\end{array}$ & $\begin{array}{l}\text { Freeze time } \\
\text { (weeks) }\end{array}$ & $\begin{array}{l}\text { Cannulation time } \\
\text { (min) }\end{array}$ & $\begin{array}{l}\text { Operational time } \\
\text { (hours) }\end{array}$ & $\begin{array}{l}\text { Fluoroscopy time } \\
\text { (sec) }\end{array}$ & $\begin{array}{l}\text { Dose area product } \\
(\mathrm{Gy} \cdot \mathrm{cm} 2)\end{array}$ \\
\hline $\begin{array}{l}\text { 1st } \\
\text { Kidney }\end{array}$ & 0.41 & 2 & 24 & 30 & Not collected & Not collected \\
\hline $\begin{array}{l}\text { 2nd } \\
\text { Kidney }\end{array}$ & 0.48 & 3 & 17 & 20 & Not collected & Not collected \\
\hline $\begin{array}{l}\text { 3rd } \\
\text { Kidney }\end{array}$ & 0.50 & 0.5 & 23 & 21 & 351 & 13.5 \\
\hline $\begin{array}{l}\text { 4th } \\
\text { kidney }\end{array}$ & 0.60 & 0.5 & 24 & 18 & 425 & 15.2 \\
\hline $\begin{array}{l}\text { 5th } \\
\text { kidney }\end{array}$ & 0.50 & 0 & 20 & 38 & 795 & 11.5 \\
\hline $\begin{array}{l}\text { 6th } \\
\text { kidney }\end{array}$ & 0.43 & 4 & $46^{*}$ & 33 & 825 & 11.5 \\
\hline
\end{tabular}

In this model, glue was the most effective embolic agent because it was not dependent on a coagulation cascade compared with Gelfoam and coils; however, utilization of glue demonstrated potential complications. In two kidneys glue adhered to the catheter tip during catheter removal post-deployment. In one kidney, the adhered glue dislodged into an unintended secondary segmental artery. These complications can also occur in the clinical practice. To prevent glue adhesion to the catheter and potential non-target embolization, the use of a microcatheter is recommended with a rapid removal from the glue cast .

Our study had several limitations. First, we used simple tap water as the perfusate. An isotonic buffer solution or blood may be more desirable to more closely mimic normal hydraulic physiology. Other perfusion models describe the use of heparinized saline or other more physiologic buffers to preserve tissue for transplantation and in ex- vivo radiofrequency ablation studies of the bovine liver (Orsi et al. 2011; Lubienski et al. 2006). Many organ perfusion models exist with protocols to extend ex-vivo viability for transplanting the kidney, liver, combined liver-kidney, lungs, heart, pancreas and small bowel using various buffers (Kumar et al. 2017; Tolstykh et al. 2002; Czogalla et al. 2016; Gao et al. 2020). We used tap water which may lead to changes in endothelial vasculature and renal parenchyma caused by a hypotonic solution. Secondly, kidneys were stored at $-20 \mathrm{C}$ for variable periods of time before they were cannulated for the procedure. The extended time in a frozen state may have led to weakening of the renal parenchyma which was noted in some kidney models that had contrast extravasation. Ideally, the kidneys should be prepared and used for the experiment within the same day of procurement without frozen storage; however, harvesting kidneys on the same day of experiments is rarely feasible. Therefore, preservation techniques should be further explored as the model is refined. Finally, we did not have histological analysis of kidneys, pre and post embolization. Another limitation we encountered was the difficulty of maintaining the flow within the closed circuit without spontaneous

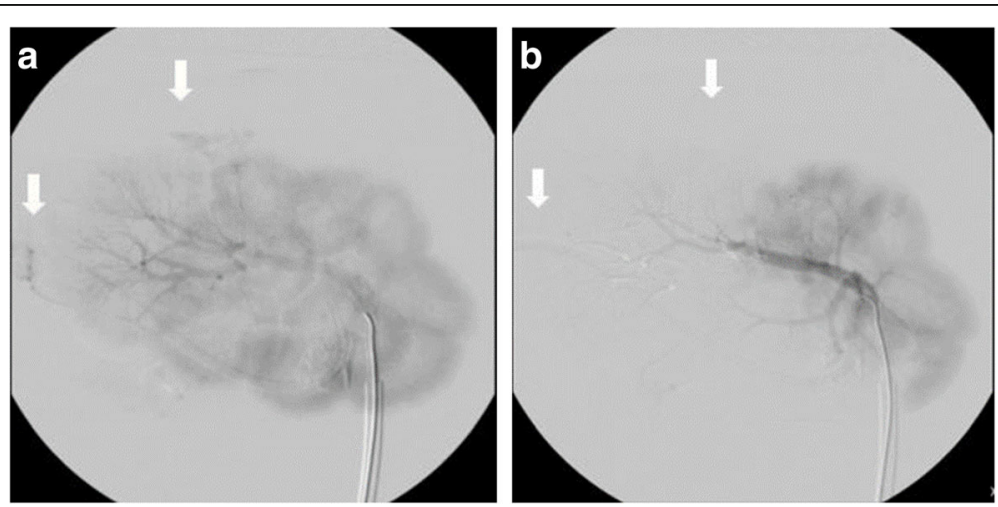

Fig. 3 a Nonselective pre-embolization DSA displaying areas of contrast extravasation (white arrows). b Nonselective post-embolization DSA. Deployment of glue in the caudal posterior segmental artery (white arrows) demonstrates appreciable embolic effect evidenced by the decreased extravasation of contrast 
decannulation of the arterial cannula. We later realized that our flow rates of $0.49 \pm 0.07 \mathrm{~L} / \mathrm{min}$ were too high. Slower, more physiologic flow rates to keep the systolic pressures between 60 and $80 \mathrm{mmHg}$ would likely help prevent these issues in future models $(5,7)$.

\section{Conclusions}

We describe the successful creation of a simple pulsatile perfusion model of a bovine kidney obtained from a slaughtered animal for testing embolic agents in an inexpensive and easy way. Given the success of the perfusion model with clinically established agents, the model may present a valid means for pretesting novel embolic agents prior to proceeding to in vivo trials. Additionally, this model can serve as a realistic educational tool to teach basic angiographic techniques such as selective vessel catherization, use of road mapping and DSA, and basic and advanced embolization techniques to inexperienced trainees.

\section{Abbreviations}

DSA: Digital subtraction angiography

\section{Acknowledgements}

None.

\section{Authors' contributions}

Luis Garza and Ryan Bitar wrote the article and were first authors with equal contributions int eh study design and data analysis. Barrett O'Donnell, Matthew Parker, Carlos Ortiz, Charles Hyman and John Walker participated in the study set up and experiments. Ho-Young Song and Jorge Lopera were the senior authors and participated in the supervision of the experiments and revisions of the article. The author(s) read and approved the final manuscript.

\section{Funding}

No funding received.

\section{Availability of data and materials}

Data is available to review.

Ethics approval and consent to participate

No ethics approval required, no liver animals or humans used in the study.

\section{Consent for publication}

yes

\section{Competing interests}

None of the authors have any conflicts of interest to disclose.

\section{Author details}

${ }^{1}$ Long School of Medicine, University of Texas Health Science Center, 7703 Floyd Curl Drive San Antonio, San Antonio, TX 78229, USA. ²Department of Radiology, University of Texas Health Science Center, San Antonio, TX, USA. ${ }^{3}$ Department of Diagnostic Radiology, Asan Medical Center, University of Ulsan College of Medicine, Seoul, Republic of Korea.

Received: 13 December 2020 Accepted: 27 January 2021

Published online: 03 February 2021

\section{References}

Barbosa L de A, Caldas JGMP, Conti ML et al (2009) Effect of renal embolization with trisacryl and PAVc. Clinics 64(11):1105-1112
Ben-Menachem Y, Coldwell DM, Young JWR et al (1991) Hemorrhage associated with pelvic fractures: causes, diagnosis, and emergent management. Am J Roentgenol. https://doi.org/10.2214/ajr.157.5.1927786

Bracken RB, Johnson DE, Goldstein HM et al (1975) Percutaneous transfemoral renal artery occlusion in patients with renal carcinoma preliminary report. Urology 6(1):6-10

Carvalho FS, Bagetti Filho HJS, Henry RW et al (2009) The bovine kidney as an experimental model in urology: external gross anatomy. Cells Tissues Organs 190(1):53-58

Czogalla J, Schweda F, Loffing J (2016) The mouse isolated perfused kidney technique. J Vis 2016(117):1-9

Feldman F, Casarella WJ, Dick HM et al (1975) Selective intra arterial embolization of bone tumors. A useful adjunct in the management of selected lesions. Am J Roentgenol. https://doi.org/10.2214/ajr.123.1.130

Gao Y, Li Z, Hong Y et al (2020) Decellularized liver as a translucent ex vivo model for vascular embolization evaluation. Biomaterials 240:119855

Kohda M, Arakawa M, Ueki H (1986) Experimental immune complex arteritis under embolization with gelatin sponge powder: a new model for induction arch. Dermatol Res. https://doi.org/10.1007/BF00407751

Kumar R, Chung WY, Dennison AR et al (2017) Ex vivo porcine organ perfusion models as a suitable platform for translational transplant research. Artif Organs. https://doi.org/10.1111/aor.12865

Lubienski A, Bitsch RG, Lubienski K et al (2006) Radiofrequency ablation (RFA): development of a flow model for bovine livers for extensive bench testing. Cardiovasc Intervent Radiol 29(6):1068-1072

Moreira PL, An YH (2003) Animal models for therapeutic embolization. Cardiovasc Intervent Radiol 26(2):100-110

Oh JS, Lee HG, Chun HJ et al (2015) Evaluation of arterial impairment after experimental gelatin sponge embolization in a rabbit renal model. Korean J Radiol 16(1):133-138

Orsi MD, Dodd GD, Cardan RA et al (2011) In vitro blood-perfused bovine liver model: a physiologic model for evaluation of the performance of radiofrequency ablation devices. J Vasc Interv Radiol 22(10):1478-1483

Siskin GP, Dowling K, Virmani R et al (2003) Pathologic evaluation of a spherical polyvinyl alcohol embolic agent in a porcine renal model. J Vasc Interv Radiol 14(1):89-98

Siskin GP, Englander M, Stainken BF et al (2000) Embolic agents used for uterine fibroid embolization. Am J Roentgenol 175:767-773

Sommer CM, Kortes N, Zelzer F et al (2011) Renal artery embolization combined with radiofrequency ablation in a porcine kidney model: effect of small and narrowly calibrated microparticles as embolization material on coagulation diameter, volume, and shape. Cardiovasc Intervent Radiol 34(1):156-165

Szymanski J, Olewnik L, Wysiadecki G et al (2018) Proposal for a new classification of the renal artery in the bovine kidney. Vet Med (Praha) 63(2):63-72

Tolstykh GP, Gelineau JF, Bunegin L (2002) Perfusion preservation of rodent kidneys in a portable preservation device based on fluidics technology. Transplantation 73(9):1508-1510

\section{Publisher's Note}

Springer Nature remains neutral with regard to jurisdictional claims in published maps and institutional affiliations.

\section{Submit your manuscript to a SpringerOpen ${ }^{\circ}$ journal and benefit from:}

- Convenient online submission

- Rigorous peer review

- Open access: articles freely available online

High visibility within the field

- Retaining the copyright to your article

Submit your next manuscript at $>$ springeropen.com 